\title{
REVISTAMARACANAN
}

Artigos

\section{O objeto artístico e o contexto histórico: a retórica de Inserções em Circuitos Ideológicos - Projeto Coca-Cola, de Cildo Meireles}

\author{
art object and the historical context: the rhetoric of Inserções em Circuitos \\ Ideológicos - Projeto Coca-Cola by Cildo Meireles
}

\author{
Fernando Aparecido Ferreira \\ Universidade de Franca \\ fferreiradg@uol.com.br
}

\author{
Fabíola Gonçalves Giraldi \\ Universidade de Franca \\ fabiolaggiraldi@gmail.com
}

\begin{abstract}
Resumo: Quando vida e obra não mais se separam, a arte passa a não mais "nascer" das mãos, mas, principalmente, da mente do artista, que se sente à vontade para, inclusive, se apropriar de qualquer objeto mundano. Objetos cotidianos são inseridos no circuito da Arte e os conceitos dessas apropriações passam a ser argumentos. O verbo torna-se parte constituinte do objeto artístico, definindo-o, contestando-o, valorizando-o. Nesse contexto, situa-se o artista brasileiro Cildo Meireles e seus ready-mades. Compreender sua proposta do ponto de vista retórico é o objetivo principal deste trabalho, que tem como objeto de estudo sua obra Inserções em Circuitos Ideológicos - Projeto CocaCola. Nossa proposta é desvelar as estratégias argumentativas empregadas pelo artista para angariar a atenção e a adesão de seu auditório à sua visão crítica e engajada sobre o papel da arte no contexto histórico-político da época (período da ditadura militar no Brasil). Este estudo se fundamenta nas exposições de Barthes acerca da retórica da imagem, bem como nos pressupostos teóricos de Meyer, Ferreira, Fiorin, Aristóteles, Reboul e Cavalcante associados às considerações de historiadores da arte brasileira.
\end{abstract}

Palavras-chave: Arte brasileira; Retórica; Argumentação; Intertextualidade; Anos 1970.

Abstract: When life and work no longer separate, art becomes not "born" from the hands, but mainly from the mind of the artist, who feels free to even take ownership of any mundane object. Everyday objects are inserted into the circuit of art and the concepts of those appropriations become arguments. The verb becomes a constituent part of the artistic object, defining it, challenging it, valuing it. In this context, lies the Brazilian artist Cildo Meireles and his ready-mades. Understanding his proposals from the rhetorical point of view is the main objective of this work, whose object of study is his work Inserções em Circuitos Ideológicos - Projeto Coca-Cola. Our proposal is unveiling the argumentative strategies employed by the artist to raise attention and the accession of his audience to his critical and committed vision about the role of art in the historical-political context of the time (period of the military dictatorship in Brazil). This research is supported in the assumptions of Barthes about the rhetoric of the image, as on the theoretical assumptions by Meyer, Ferreira, Fiorin, Aristotle, Reboul and Cavalcante, associated with the considerations from historians of Brazilian art.

Keywords: Brazilian art; Rhetoric; Argumentation; Intertextuality; 1970s. 


\title{
Introdução
}

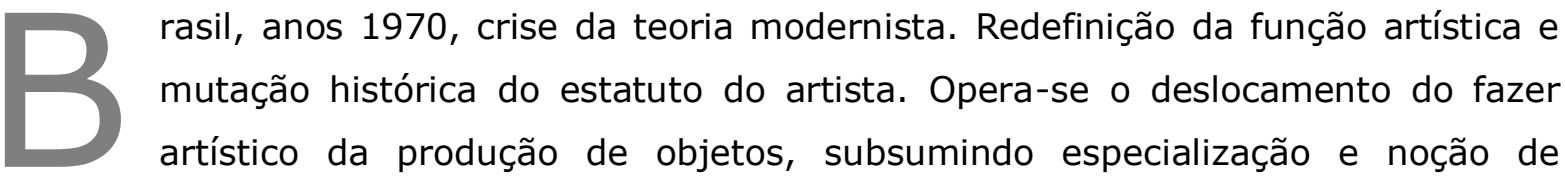
originalidade e unicidade da obra, para a constituição de uma rede de significações, com a exploração sistemática da combinação de diferentes meios, artísticos ou não, e a contaminação entre as artes.

Objetos do cotidiano inserem-se no circuito artístico e os conceitos dessas invenções manifestados também através do verbo tornam-se parte constituinte do objeto artístico, seja para comentá-lo, interpretá-lo, defini-lo, contestá-lo ou valorizá-lo.

Deixa de existir, de um lado, a obra e, de outro, os discursos sobre ela. Os diferentes domínios materiais, técnicos e simbólicos e suas interpenetrações são também artes do dizível, - que contribui para a abertura desse complexo pensamento visual que exprime a exterioridade e a intimidade do artista. O trabalho de arte pensa e faz pensar.

No período em que o Brasil vive um endurecimento da ditadura militar, a arte também se politiza, mas em seus próprios termos, conforme ressalta a historiadora de arte Glória Ferreira. Em seu texto que abre o livro-catálogo Anos 70 - Arte como questão, Ferreira explica:

\begin{abstract}
Em contexto de transgressão dos valores e resistência à ditadura e à racionalização da vida social, opera-se uma mutação do que seria a arte política: sem subordinação às políticas partidárias, a práxis artística se apoiará no deslocamento do debate artístico do terreno ideológico - de dar formas a conteúdos políticos - para uma política das artes inscrita na própria linguagem e nas modalidades de sua inserção na sociedade. ${ }^{1}$
\end{abstract}

A arte brasileira dos anos 1970 reflete o rumo das vanguardas do final da década anterior, em que a experimentação artística se radicaliza, e revela suas possibilidades de, em termos formais, agregar crítica política e social, conforme observa Paulo Reis. ${ }^{2}$

Nesse contexto histórico, situa-se o artista carioca Cildo Meireles, cujos ready-mades, diferentes dos duchampianos, não saem do coloquial para os lugares da arte, e sim levam o pensamento artístico para a circulação cotidiana. Sobre os ready-mades, tomemos como exemplo a obra Fountain, de Marcel Duchamp (Figura 1):

\footnotetext{
${ }^{1}$ FERREIRA, Glória. Anos 70: Arte como questão. São Paulo: Instituto Tomie Ohtake, 2007. p. 25.

2 REIS, Paulo. Arte de vanguarda no Brasil: os anos 60. Rio de Janeiro: Jorge Zahar, 2006. p. 74.
} 


\section{Figura 1}

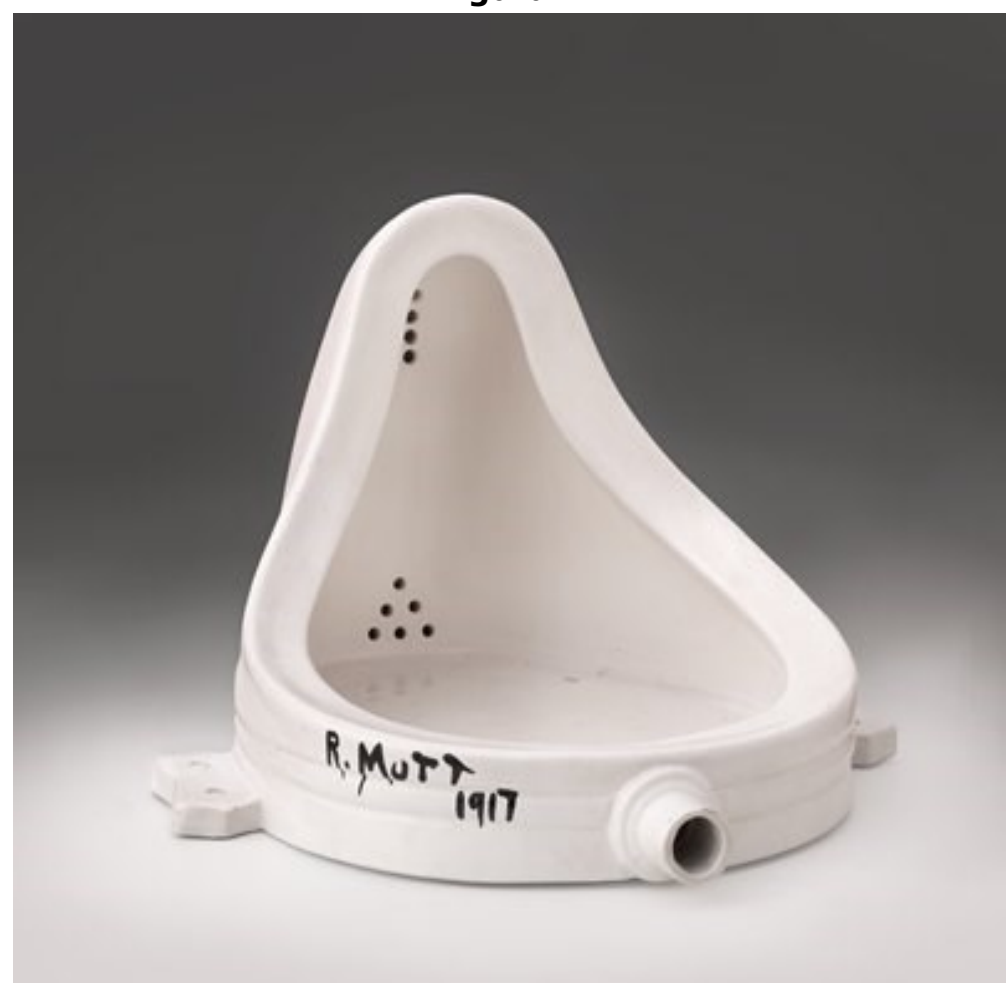

Fountain, Marcel Duchamp, 1917.

Fonte: < https://www.sfmoma.org/artwork/98.291\#> Acesso em:20/05/2015.

Marcel Duchamp (1887-1968) é um dos artistas mais comentados, estudados e referenciados do mundo da arte devido à, segundo Gompertz, "sua nova forma de fazer arte", a que chamou de ready-made: uma escultura já pronta. Objetos são retirados de seus lugares corriqueiros, de uso cotidiano, e levados ao status de objetos de arte. Tais escolhas libertam a arte do fazer manual (artesanal) e conectam-na a uma ideia, a um saber mental que o artista detém sobre sua criação. Além disso, esse procedimento desmitifica a figura do artista, afinal, segundo Cristina Freire:

O ready-made, como objeto industrial sem qualquer apelo estético, tornase paradigma de uma operação na qual a autoria é compartilhada [...], Duchamp lança as premissas para se compreender o que veio a ser a participação do espectador na arte contemporânea. ${ }^{4}$

Pode-se dizer que Fountain é o ready-made mais famoso de Marcel Duchamp. De um mictório comprado numa loja qualquer e colocado de maneira a parecer estar de cabeça para baixo, assinado e datado "R. Mutt 1917" e, tendo como título Fountain (Fonte), Duchamp faz então uma obra de arte.

Recontextualizando, para artistas como Cildo Meireles, objetos não são escolhidos ao acaso; suas provocações, ideias e pensamentos são expressos também por objetos escolhidos

\footnotetext{
3 GOMPERTZ, Will. Isso é arte? 150 anos de arte moderna do impressionismo até hoje. Rio de Janeiro: Jorge Zahar Editor Ltda., 2013. p. 21.

${ }^{4}$ FREIRE, Cristina. Arte conceitual. Rio de Janeiro: Zahar, 2006. p. 35.
} 
estrategicamente pelas suas conotações históricas, políticas, sociais, culturais, sendo inseridos criticamente na realidade cotidiana. Segundo declaração própria:

\begin{abstract}
Em grande parte da minha obra há uma interpenetração entre o trabalho de arte e a vida diária, e isso afeta a escolha do material. Estou interessado em materiais ambíguos, que podem simultaneamente ser símbolo e matéria-prima, assumindo status de objetos paradigmáticos. Os materiais que podem conter essa ambiguidade vão de fósforos a garrafas de Coca-Cola, de moedas a cédulas ou a uma vassoura, como em La bruja (1979-81). Estão no mundo cotidiano, próximos de suas origens, e, apesar disso, impregnados de significados. ${ }^{5}$
\end{abstract}

Assim, é impossível desconsiderar essas conotações quando se fala em Brasil dos anos 1970. Os contextos sociopolíticos provenientes da ditadura militar como repressão, tortura, indústria cultural, ideologias, luta armada, censura, assassinatos, milagre econômico e exílio eram tão efervescentes que não escapavam às novas possibilidades da arte.

Manifestos de artistas brasileiros de vanguarda do final dos anos 1960 pregavam uma postura revolucionária. Em um dos trechos da Declaração dos Princípios Básicos da Vanguarda, que precedeu a importante mostra "Nova objetividade brasileira", realizada em 1967, no MAM do Rio Janeiro, vinha uma proposta de "integrar a atividade criadora na coletividade, opondose inequivocamente a todo isolacionismo dúbio e misterioso, ao naturalismo ingênuo e às insinuações de alienação cultural". ${ }^{6}$ A Declaração também destacava uma postura crítica ao mercado artístico:

O movimento nega a importância do mercado de arte em seu conteúdo condicionante; aspira acompanhar as possibilidades da revolução industrial alargando os critérios de atingir o ser humano, despertando-o para a compreensão de novas técnicas para a participação renovadora e para a análise crítica da realidade. ${ }^{7}$

O poder crítico e a luta pela liberdade de expressão, aliados ao experimentalismo, contribuíram para que a arte saísse dos museus e das galerias e invadisse o espaço onde as pessoas pudessem vivenciá-las. O campo artístico expande-se e as ações artísticas cotidianas integradas pelos seus projetos e registros, não mais uma obra única e original, misturam-se, tornando quase impossível separar arte e vida. Segundo Hal Foster, crítico e historiador de arte norte-americano: "O artista torna-se um manipulador de signos, mais do que um produtor de objetos de arte, e o espectador, um ativo leitor de mensagens mais do que um contemplador estético ou um consumidor do espetáculo". 8

5 MONACHESI, Juliana. Situações cariocas. Canal Contemporâneo, 2007. Disponível em: < http://www.canalcontemporaneo.art.br/arteemcirculacao/archives/001539.html>. Acesso em: 25/11/2014.

6 RIDENTI, Marcelo. Em busca do povo brasileiro: artista da revolução, do CPC à era da TV. Rio de Janeiro: Record, 2000. p. 189.

7 RIDENTI, Marcelo. Op. cit., p. 189.

8 FOSTER, Hal apud FREIRE, Cristina. Op. cit., p. 38. 
Entre tantos trabalhos de Cildo Meireles, justamente por tratar das questões expostas, uma obra foi escolhida para produção deste trabalho: Inserções em Circuitos Ideológicos: Projeto Coca-Cola, de 1970.

Nessa obra, Meireles tira temporariamente de circulação garrafas de Coca-Cola e, a partir de técnicas de serigrafia, imprime nelas, além do título do projeto, informações verbais como: a orientação "Gravar nas garrafas opiniões críticas e devolvê-las à circulação"; a expressão "Yankees, go home"; e o nome de desaparecidos políticos ou pessoas postas "fora de circulação" pelo regime militar então em vigência no Brasil. O artista também abre a possibilidade de interação do público com a obra, permitindo que qualquer um imprima suas opiniões críticas nas garrafas que, ao final desse processo, eram repostas em circulação. Nas palavras de Glória Ferreira, Inserções em Circuitos Ideológicos é uma obra "[...] cuja poética se funda em uma rede de referências históricas, políticas, sociais e econômicas". ${ }^{9}$

Abordando a obra de Meireles como um texto sincrético, o qual, segundo o linguista Fiorin, ${ }^{10}$ é um texto produzido a partir da conjunção de várias linguagens (gráfica, sonora, visual, audiovisual) num único arranjo, este trabalho tem por objetivo buscar desvelar suas estratégias argumentativas construídas pelo uso das figuras de retórica e formas de intertextualidade, considerando quais efeitos produzem em seu auditório ${ }^{11}$ que ora intenciona ser o público em geral, ora um auditório particular constituído por críticos e instituições de arte.

Os fundamentos teóricos escolhidos para a análise aqui proposta incluem os estudos de Roland Barthes expostos no artigo Retórica da imagem, que trata da eloquência do imagético (suas denotações e conotações) e das funções que o verbal exerce "para frear" essa polissemia, bem como os estudos retóricos desenvolvidos por Meyer, Perelman e OlbrechtsTyteca, Fiorin e Aristóteles. Noções advindas da Linguística Textual trazidas por Cavalcante também foram evocadas, como as relacionadas à intertextualidade.

\footnotetext{
9 FERREIRA, Glória. Apresentação. In: FERREIRA, Glória; COTRIM, Cecília (Org.). Escritos de artistas: anos 60/70. 2. ed. Rio de Janeiro: Jorge Zahar, 2009. p. 26. Cabe aqui destacar que, embora não analisado neste artigo, Inserções em Circuitos Ideológicos também contempla o Projeto Cédula, no qual cédulas de cruzeiro (a então moeda brasileira) eram carimbadas com textos com as mesmas instruções do Projeto Coca-Cola e frases como "Which is the place of the work of art?" (Qual é o lugar da obra de arte?) e "Quem matou Herzog?", entre outras.

10 FIORIN, José Luiz. Para uma definição das linguagens sincréticas. OLIVEIRA, Ana Cláudia de; TEIXEIRA, Lúcia. (Orgs.). Linguagens na comunicação: desenvolvimentos de semiótica sincrética. São Paulo: Estação das Letras e Cores, 2009. p. 38.

${ }^{11} \mathrm{Em}$ retórica, o auditório é "conjunto daqueles que o orador quer influenciar com sua argumentação" (PERELMAN, Chaïm; OLBRECHTS-TYTECA, Lucie. Tratado da argumentação: a nova retórica. São Paulo: Martins Fontes, 2005. p. 22).
} 


\section{Retórica da imagem}

Segundo Barthes, ${ }^{12}$ "toda imagem é polissêmica e pressupõe, subjacente a seus significantes, uma 'cadeia flutuante' de significados, podendo o leitor escolher alguns e ignorar outros".

Essa escolha feita pelo leitor depende de como cada sociedade desenvolve as técnicas destinadas a "fixar" essa polissemia, essa cadeia flutuante de significados, para que não haja o risco dos signos incertos, das interpretações errôneas. A mensagem linguística é uma dessas técnicas; "trata-se de uma descrição denotada da imagem, [...] corresponde a uma fixação de todos os sentidos possíveis (denotados) do objeto", ${ }^{13}$ permitindo que o leitor possa adaptar e orientar seu olhar e seu intelecto à imagem a ser interpretada a partir do que se queira significar.

Segundo Barthes, essa mensagem linguística pode ter duas funções: de ancoragem (fixação) ou de revezamento. A primeira, e mais frequente, consiste em utilizar-se da nomenclatura para a fixação de todos os sentidos possíveis e orienta a leitura da imagem através de legendas, títulos e outras palavras que a acompanham; dessa maneira, "o texto conduz o leitor por entre os significados da imagem, fazendo com que se desvie de alguns e assimile outros, [...] ele o teleguia em direção a um sentido escolhido a priori" (1990, p. 33). Ademais, para o autor,

O texto é realmente a possibilidade do criador (e, logo, a sociedade) de exercer um controle sobre a imagem: a fixação é um controle, detém uma responsabilidade sobre o uso da mensagem, frente ao poder de projeção das ilustrações; o texto tem um valor repressivo em relação à liberdade dos significados da imagem; compreende-se que seja ao nível do texto que se dê o investimento da moral e da ideologia de uma sociedade. ${ }^{14}$

Essa última função é mais comum em fotografia jornalística e em publicidade, mas não apenas (como no exemplo analisado neste trabalho). O revezamento é encontrado, sobretudo, em charges e histórias em quadrinhos, em que a palavra e a imagem têm uma relação de complementaridade.

Vejamos, então, na imagem a seguir (Figura 2), a obra que constitui o objeto de estudo deste trabalho.

\footnotetext{
12 BARTHES, Roland. Retórica da Imagem. In: BARTHES, Roland. O óbvio e o obtuso: ensaios críticos III. Tradução: Léa Novaes. Rio de Janeiro: Nova Fronteira, 1990. p. 32.

${ }^{13}$ Id.

14 Ibidem, p. 33.
} 
Figura 2

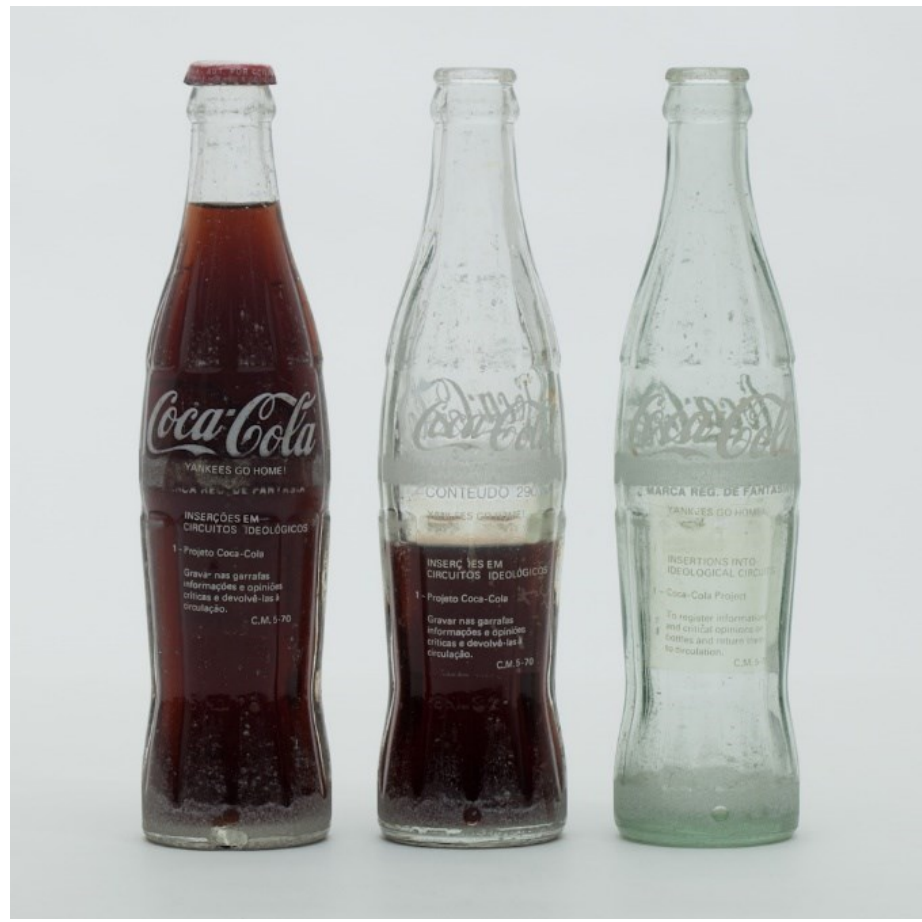

Inserções em Circuitos Ideológicos - Projeto Coca-Cola, Cildo Meireles, 1970.

Fonte: <http://revistacarbono.com/wp-content/uploads/2013/09/CildoMeireles\%C2\%A9PatKilgore20119890.jpg > Acesso em: 22/11/ 2014.

Nessa reprodução fotográfica de parte do projeto do artista plástico carioca Cildo Meireles (nascido em 1948), Inserções em Circuitos Ideológicos - Projeto Coca-Cola, temos a imagem de três garrafas de vidro de Coca-Cola, cada uma delas com quantidades diferentes da bebida. Conforme já dito, esse projeto consistia em escrever na superfície dos vasilhames vazios do refrigerante (que eram retornáveis ao fabricante), instruções sobre como o público (qualquer pessoa) deveria proceder para inserir as próprias "opiniões críticas", além do nome do projeto, uma frase em inglês e outras informações verbais.

Refletindo sobre as questões levantadas por Barthes, nessa imagem temos uma mensagem linguística cuja função é a de ancoragem, pois contribui para a fixação do sentido idealizado pelo orador, ${ }^{15}$ nesse caso, pelo artista Cildo Meireles. As palavras impressas na garrafa de Coca-Cola acomodam o intelecto, direcionam a certas leituras, que são variáveis nos indivíduos, uma vez que dependem de seus diferentes saberes.

A mensagem linguística da obra de Meireles é a seguinte:

\author{
Coca-Cola \\ YANKEES GO HOME! \\ MARCA REG. DE FANTASIA \\ INSERÇÕES EM
}

\footnotetext{
15 O orador é aquele que, por meio do discurso, quer atingir o outro, para ensiná-lo, comovê-lo e agradálo (FERREIRA, Fernando Aparecido. As paixões de "Furico \& Fiofó": estratégias retóricas de um desenho animado. In: FIGUEIREDO, Maria Flávia et al. (Org.) Textos: sentidos, leituras e circulação. Coleção Mestrado em Linguística. V. 9. UNIFRAN: Franca, SP, 2014. p. 77).
} 


\title{
CIRCUITOS IDEOLÓGICOS
}

1-Projeto Coca-Cola

Gravar nas garrafas opiniões críticas e devolvê-las à circulação.

CM-5-70.

Diante desse contexto, podemos encontrar alguns signos, algumas representações, pois, como pondera Barthes, signos de conotação impregnam toda a imagem.

\begin{abstract}
Nunca se encontra uma imagem literal em estado puro; mesmo que conseguíssemos elaborar uma imagem inteiramente "ingênua", a ela se incorporaria, imediatamente, o signo da ingenuidade e a ela se acrescentaria uma terceira mensagem, simbólica. ${ }^{16}$ (Grifo do autor)
\end{abstract}

Portanto, daquilo que temos como descrição, como uma mensagem icônica denotada três vasilhames de vidro de Coca-Cola, de 290 ml, contendo inscrições acrescidas em seu rótulo, cada uma com uma quantidade da bebida -, podemos conjecturar alguns significados como: consumismo, influência e intervenção da cultura norte-americana, circulação de mercadoria, circuito de arte, valor do objeto artístico, arte participativa.

As mensagens conotadas que essa imagem carrega podem variar de acordo com os indivíduos que têm acesso a elas. Diante dos significados identificados, podemos perceber que uma garrafa de Coca-Cola representa o consumismo globalizado, imposto por outra cultura. O fato de uma garrafa ser retornável significa "mandar de volta a quem me enviou" para que a circulação da mercadoria continue ativa. Essa mensagem pode ser considerada de fácil apreensão por qualquer pessoa que identifique o refrigerante. Mesmo que essa pessoa não consiga entendê-la com profundidade, conseguirá situar parte do contexto.

Ao utilizar um objeto-símbolo da cultura norte-americana, o artista traz esta crítica: o repúdio à política de intervenção econômica, política e cultural norte-americana (Yankees, go home).

A mercadoria é circulante, o artista devolve sua impressão/crítica/percepção dessa influência àqueles que a colocam no mercado, à marca (empresa), bem como contribui/possibilita que outras pessoas o façam. Além disso, o artista questiona o papel do artista, do autor da obra e convida o consumidor/espectador a participar de sua criação, assim como restabelece uma relação da obra de arte com o mercado: o objeto de arte "passeia" pelas pessoas e não mais espera que elas venham até ele.

Questões estéticas relacionadas a outros contextos históricos da arte são postas em cena, retomadas. A Arte Pop é exemplo disso, quando objetos de uso cotidiano e popular saem de seus lugares no mercado e tomam espaços de galerias e museus: as garrafas de Coca-Cola estão circulando, mas são objetos de consumo popular que passam a ser objetos artísticos. Os ready-mades, de Marcel Duchamp, também são lembrados, quando o produto artístico é executado sobre um objeto do cotidiano, é libertado do domínio das mãos do artista.

16 BARTHES, Op. cit., p. 34. 
A leitura, portanto, não se esgota, pois deixa rastros de interpretações e indícios de ideologias e fixações de sentidos. Mas, como vimos no início, cada leitor/espectador escolhe alguns e não outros significados. Conforme afirma Barthes:

Todas as obras de comunicação de massa reúnem, por meio de dialéticas diversas e diversamente performantes, a fascinação de uma natureza, que é a natureza da narrativa, da diegese, do sintagma, e a inteligibilidade de uma cultura, refugiada em alguns símbolos descontínuos, que os homens "declinam" sob a proteção da palavra viva. ${ }^{17}$ (Grifo do autor)

Diante de símbolos construídos e reconstruídos pelos homens, imersos nessa liberdade de escolher seus significados, o verbo conquista sua legibilidade e possibilita que os próprios homens identifiquem-se, reconheçam-se, afastem-se ou aproximem-se. A palavra, desse modo, confirma as escolhas e opiniões do homem diante de suas percepções do mundo. Pensar em como e para quem as palavras são ditas, além de buscar entender como esse dizer pode ser eficaz e compreendido, é o objeto de estudo da retórica.

\title{
Estratégias retóricas
}

Mesmo sendo a arte considerada uma obra aberta, os textos e discursos verbais a acompanham e, segundo Umberto Eco:

\begin{abstract}
Não tende a nos definir a realidade de modo unívoco, definitivo, já confeccionado, pois precisamos fazer um esforço para compreendê-las, para torná-las familiares, precisamos intervir com atos de escolha, construir-nos a realidade sob o impulso da mensagem estética, sem que esta nos obrigue a vê-la de um modo predeterminado, essa se apoia em fragmentos verbais que nos possibilitam perceber indícios de um discurso que nos leva não a pensar de forma única mas nos direciona a desejar, compreender, temer, querer e não querer, concordar ou discordar. ${ }^{18}$
\end{abstract}

Todo discurso é, por excelência, uma construção retórica, uma vez que procura conduzir o auditório numa direção determinada e projetar um ponto de vista. Sendo discurso, nas palavras de Reboul, ${ }^{19}$ "toda produção verbal, escrita ou oral, constituída por uma frase ou por uma sequência de frases, que tenha começo e fim e apresente certa unidade de sentido", podemos considerar que a manifestação discursiva, conforme expõe Fiorin, ${ }^{20}$ constrói nossa maneira de ver a realidade e dela podemos extrair a originalidade, a individualidade e a subjetividade do sujeito que a faz pretendendo persuadir (convencer ou comover).

\footnotetext{
17 Ibidem, p. 42.

18 ECO, Umberto apud CITELLI, Adilson. Linguagem e persuasão. São Paulo: Ática, 1995. p. 68.

19 REBOUL, Olivier. Introdução à retórica. Tradução: Ivone Castilho Benedetti. São Paulo: Martins Fonte, 2004. p. XIV.

${ }^{20}$ FIORIN, José Luiz. Figuras de retórica. São Paulo: Cortez, 2014. p. 12-14.
} 
Ao fazer uma análise pelo viés da retórica, é importante notar que "o objeto desta teoria é o resultado das técnicas discursivas que permitem provocar ou aumentar a adesão dos espíritos às teses que lhes apresentam ao assentimento". ${ }^{21}$

Sempre que há uma questão polêmica no âmbito da linguagem, ou seja, uma questão que foge de certezas ou evidências lógicas, pode-se explorar discursivamente o campo do verossímil, das possibilidades, dos conhecimentos prováveis e é, então, que aquele que melhor se expressa sobre tal assunto se sobressai, o que nos leva a dizer que ele domina melhor a linguagem. De acordo com Luiz Antônio Ferreira, "nesse espaço do dizer, em que a habilidade no manejo do discurso se impõe potentemente para que o orador consiga mover seu auditório a favor de suas causas, habita a retórica".22

A definição da retórica é conhecida: é a arte de bem falar, de mostrar eloquência diante de um público para ganhar a sua causa. Isso vai da persuasão à vontade de agradar. ${ }^{23}$

Para os antigos, a retórica englobava tanto a arte de bem falar como o estudo do discurso ou as técnicas de persuasão e até mesmo de manipulação (modos de exprimir, estilo, a justeza das teses defendidas, a justiça).

Ainda de acordo com a tradição, a retórica foi definida como a arte de bem falar e, segundo Aristóteles, "a capacidade de descobrir o que é adequado a cada caso com o fim de persuadir", ${ }^{24}$ mas, a partir de sete objetivos básicos sugeridos por Meyer, pode ser assim redefinida:

1. persuadir e convencer, criar o assentimento;

2. agradar, seduzir ou manipular, justificar (por vezes a qualquer preço) as nossas ideias de forma a fazê-las passar por verdadeiras, quer 0 sejam, quer acreditemos que o sejam;

3. fazer passar o verossímil, a opinião e o provável com boas razões e argumentos, sugerindo inferências ou tirando-as por outrem;

4. sugerir o implícito através do explícito;

5. instituir um sentido figurado, através de figuras de estilo e "histórias", inferidas ou decifráveis do sentido literal;

6. utilizar uma linguagem figurada e estilizada, o literário;

7. descobrir as intenções daquele que fala ou escreve, conseguir atribuir razões para o seu dizer, entre outras coisas, através do que é dito. ${ }^{25}$

Diante disso, a retórica não poderia se limitar à arte de persuadir, pois, diante de uma questão ou tese a ser colocada em reflexão, que pode ser por meio de um texto verbal, visual ou mesmo sincrético, há um orador tratando com um auditório, alguém que se revela e se expõe a outra pessoa estabelecendo uma relação que pode ser não necessariamente de persuasão.

Segundo Michel Meyer:

\footnotetext{
${ }^{21}$ PERELMAN, Chaïm; OLBRECHTS-TYTECA, Lucie. Op. cit., p. 4.

22 FERREIRA, Luiz Antônio. Leitura e persuasão: princípios de análise retórica. São Paulo: Contexto, 2010. p. $14-15$.

${ }^{23}$ MEYER, Michel. Questões de retórica: linguagem, razão e sedução. Lisboa: Edições 70, 2007. p. 17.

24 ARISTÓTELES. Retórica. Lisboa: Imprensa Nacional - Casa da Moeda, 2005. p. 96.

25 MEYER, Michel. Op. cit., p. 22.
} 
Veicular o implícito não é necessariamente sugerir uma conclusão para convencer quem quer que seja, mas pode simplesmente querer significar qualquer coisa a alguém, informá-lo do que pensamos sobre uma questão que é colocada expressamente ou não. ${ }^{26}$

A sociedade nos alimenta com questões. Os homens definem seus valores aproximando-se de uns e afastando-se de outros a partir do quanto esses debates diante dos diversos argumentos e teses que lhes são colocados interferem em suas colocações.

Como menciona Meyer:

Segundo Aristóteles, não nos interrogamos sobre o problemático: discutimos teses opostas sobre as quais uma maioria de pessoas ou de sábios com autoridades estão em desacordo, e a propósito das quais eles formam portanto um novo acordo. Estas teses só são defensáveis se a sua verdade já é provável e mais ou menos assegurada. ${ }^{27}$

Dessa forma, a retórica trata de causas ou teses a defender (mas todas são questões), bem como atua na identidade e na diferença entre indivíduos por meio de questões pontuais que estabelecem sua distância. E, ainda segundo Meyer,

[...] quando tratamos de uma questão, qualquer que seja ela, pronunciamo-nos sempre indirectamente sobre ela e, ao mesmo tempo, aceitamos que ela se coloque ou que seja recusada; resumindo, exprimimos de facto uma opinião sobre a sua pertinência. ${ }^{28}$ (Grifos do autor)

Cildo Meireles apresenta-nos uma questão e, fazendo uso de figuras de retórica recursos de linguagem enunciativa para intensificar o sentido de certos elementos do discurso - como a metáfora, a metonímia e a ironia, e do emprego da citação, da alusão e da paródia, formas de intertextualidade, busca angariar a atenção e a adesão de seu auditório à sua visão crítica e engajada sobre o papel da arte e o contexto sociopolítico no qual ela se insere.

\section{Questões de Cildo: o circuito da arte}

Quando Cildo Meireles escolhe as garrafas de Coca-Cola para expor suas reflexões acerca do universo artístico, não o faz aleatoriamente, por pura provocação. Suas questões estão ligadas ao contexto histórico-político em que vivia. Está aí a base da arte conceitual da qual faz parte seu fazer, arte que se preocupa primeiramente com a ideia e depois com qual a melhor forma de expressá-la.

Ao utilizar as garrafas de Coca-Cola, o artista atinge um auditório universal, aquele sobre o qual não há como se ter o controle, uma vez que muitas pessoas podiam ter em mãos as "suas" garrafas e um auditório particular, composto pela instituição arte que, ao também

\footnotetext{
${ }^{26}$ Ibidem, p. 27.

27 Ibidem, p. 29.

28 Ibidem, p. 38.
} 
criticar, expor ou comprar seu trabalho, se apropria da sua ideia. As garrafas não eram dele. Logo, sua intenção não era se apropriar das garrafas para que fizesse delas mercadoria.

Analisando suas estratégias, podemos identificar alguns recursos utilizados pelo artista (orador) para conseguir atingir seu objetivo. A metáfora e a metonímia são dois deles. Uma, por similaridade, por unir traços comuns a dois significados que coexistem, dando tonicidade ao sentido; outra, por contiguidade, proximidade, por estabelecer uma compatibilidade entre os dois sentidos. ${ }^{29}$

Tais recursos podem ser identificados, quase que simultaneamente, quando a garrafa de Coca-Cola, símbolo do capitalismo, representa o colonialismo norte-americano criticado por ele. Não é em si o refrigerante o objeto da crítica do artista, mas tudo o que envolve a imposição de uma cultura estrangeira sobre a nacional.

Quase que ao mesmo tempo, Cildo utiliza a ironia, entendida por Fiorin ${ }^{30}$ como "um tropo em que se estabelece uma compatibilidade predicativa por inversão, alargando a extensão sêmica dos pontos de vista coexistentes e aumentando sua intensidade" e cuja finalidade, geralmente, é criticar.

Cildo, ao questionar o próprio circuito da arte e os objetos de consumo, que também fazem parte da arte, e ao inserir indicações para que o consumidor participe da obra, assume táticas (irônicas) desviantes, produtoras de movimentos, em deslocamento constante, que evitam posições fixas e o isolamento de outras atividades e outros conhecimentos. Seria ingênuo acreditar que se possa falar a respeito de arte sem pressupor a existência de um "campo social autônomo" amparado pelo circuito de arte.

Nesse sentido, ao mesmo tempo que o artista lança questões críticas acerca da macroindústria econômica, coloca em questão a instituição arte.

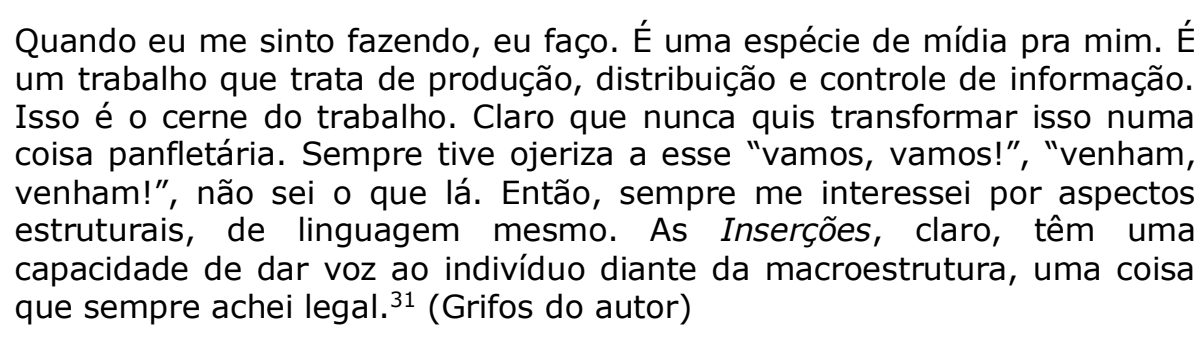

Tal como Marcel Duchamp, Cildo consegue a atenção do seu auditório particular quando ironicamente critica o circuito da arte, o que acaba sendo um artifício retórico que cria uma predisposição (ou um interesse inicial) para as questões que ele quer discutir.

Ao indagar sobre o lugar do artista e espectador e do próprio objeto artístico, Cildo provoca o circuito de arte colocando a importância de tornar presente a participação do

\footnotetext{
${ }^{29}$ FIORIN, José Luiz. Op. cit., 2014.

${ }^{30}$ Ibidem, p. 70.

31 FRAGA, Marina; URANO, Pedro. Carbono entrevista Cildo Meireles. Revista Carbono. 2013. Disponível em: <http://revistacarbono.com/artigos/04carbono-entrevista-cildo-

meireles/\#sthash.nLnoMhg0.OCEQD9D6.dpuf>. Acesso em: 25/11/2014.
} 
espectador, desmitificar a figura do artista e usar lugares e formas alternativas de circulação das proposições artísticas.

Além dessas estratégias argumentativas utilizadas por Cildo, observadas pelo prisma da retórica, recorremos também à intertextualidade para ampliar a análise de sua obra, uma vez que podemos reconhecer nela relações com outros textos.

Considerando, de acordo com os estudos de Julia Kristeva, que todo texto é constituído por "[...] uma sucessão de textos já escritos ou que ainda serão escritos"32 e que, segundo Bakhtin, "[...] um texto não existe nem pode ser avaliado e/ou compreendido isoladamente: ele está em diálogo com outros textos e dele fazem parte outros textos que lhe dão origem, que o predeterminam, com os quais dialoga, que ele retoma, a que alude ou aos quais se opõe", 33 é possível identificar algumas formas de intertextualidade nos trabalhos de Cildo Meireles.

As relações entre os textos, resumidas por Piègay-Gros, ${ }^{34}$ podem ser relações de copresença: citação, referência, plágio e alusão; e relações de derivação: a paródia, o travestismo burlesco e o pastiche. Assim sendo, uma estratégia utilizada por Cildo é a alusão, que, como menciona Mônica Cavalcante:

É uma espécie de referenciação indireta, como uma retomada implícita,
uma sinalização, para o coenunciador de que, pelas orientações deixadas
no texto, ele deve apelar à memória para encontrar o referente não dito
[...], a alusão não apresenta marcas diretas e, portanto, seu
reconhecimento demanda maior capacidade de inferência por parte do
enunciador. Nem sempre um coenunciador detém as informações
necessárias para o reconhecimento dos indícios intertextuais da referência
e, principalmente, da alusão, mas essa possibilidade não faz com que o
fenômeno deixe de existir, pois se um leitor não conseguir alcançar a
intertextualidade, outro, certamente, o fará. ${ }^{35}$

Ao utilizar as garrafas de Coca-Cola em seu trabalho, remetendo a Marcel Duchamp, que também desmitifica a figura do artista com sua obra, Cildo Meireles lança mão da intertextualidade como uma estratégia importante, mesmo que não explícita.

Além da duchampiana, não há como negar a forte influência da Arte Pop americana quando estamos diante da garrafa de Coca-Cola, mais especificamente do trabalho de artistas como Robert Rauschenberg e Andy Warhol. O primeiro (vindo do Expressionismo Abstrato, mas chegando até a Arte Pop) utilizava materiais considerados lixo e os misturava com técnicas de pintura, escultura e colagem, obtendo objetos tridimensionais nomeados de combines; para ele, o espectador é quem finaliza a obra, é ele quem faz a imagem. O segundo reproduzia repetidamente imagens extraídas da banalidade cultural americana como objetos

\footnotetext{
${ }^{32} \mathrm{KOCH}$, Ingedore G. Villaça et al. Intertextualidade: diálogos possíveis. São Paulo: Cortez, 2008. p. 9.

33 BAKHTIN, Mikhail apud KOCH, Ingedore G. Villaça et al. Op. cit., p. 9.

34 PIĖGAY-GROS apud CAVALCANTE, M. M. Os sentidos do texto. São Paulo: Contexto, 2013. p. 146.

35 CAVALCANTE, M. M. Op. cit., p. 152.
} 
de consumo diário ou personalidades populares (Figura 3), reiterando a ideia de obra de arte como mercadoria. ${ }^{36}$

Figura 3

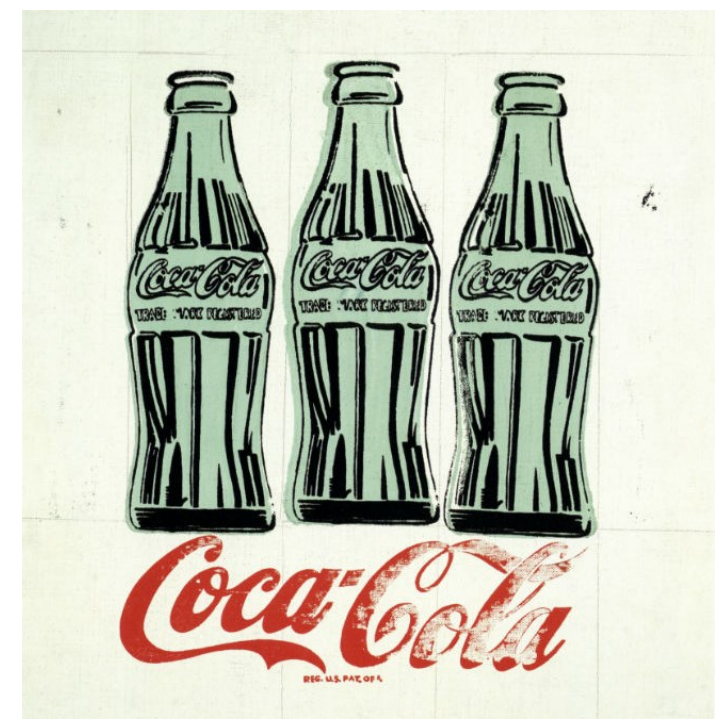

3 Coke Bottles, Andy Warhol, 1962.

Fonte: <http://www.forbes.com/sites/abinlot/2015/03/25/andy-warhols-coca-cola-art-highlighted-inexhibition-commemorating-the-bottles-100th-anniversary/\#3b50a6e32a86> Acesso em: 10/07/2015.

Assim como Cildo Meireles, Rauschenberg e Warhol reiteravam questões no mundo da arte indagando seu contexto em relação ao próprio sistema. Escolher um objeto em meio à multiplicidade de tantos outros e dar-Ihe um novo significado, mesmo que não o tire totalmente de seu referencial, contribui para os pensamentos e ideias investigativas desses artistas que relacionam e misturam arte à cultura visual de massa.

Nesse sentido, Cildo corresponde às iniciativas dos movimentos de vanguarda surgidos no Brasil após o Golpe Militar de 1964, que buscavam, na sua relação com a cultura de massa, "absorver e superar certa banalização da Arte Pop" e também "ressignificar a operação do readymade". ${ }^{37}$

A alusão aos ready-mades e aos trabalhos dos expoentes da Pop Art se apresenta como uma estratégia retórica, já que para Cildo "as Inserções em circuitos ideológicos tinham essa presunção: fazer o caminho inverso ao dos readymades. Não mais o objeto industrial colocado no lugar do objeto de arte, mas o objeto de arte atuando no universo industrial" ${ }^{38}$.

\footnotetext{
36 ARCHER, M. Arte contemporânea: uma história concisa. Tradução: Alexandre Krug e Valter Lellis Siqueira. São Paulo: Martins Fontes, 2001. p. 3-10.

37 REIS, Paulo. Op. cit., p. 42.

38 FERREIRA, Glória; COTRIM, Cecília. Op. cit., p. 264.
} 


\section{Considerações finais}

Diante de um mundo cada vez mais imagético - o que não podemos dizer ser algo próprio apenas dos nossos dias, mas sim que as imagens nos chegam cada vez mais cedo, rápida e intensamente - , é bem possível fazermos interpretações retóricas dessas imagens. $\mathrm{E}$ para isso é fundamental que se considere sempre o seu contexto histórico.

Assim, abordar brevemente o contexto em que se insere o artista Cildo Meireles é o que buscou este trabalho: compreender - pelo viés da retórica e noções de intertextualidade, com as contribuições de Barthes - como o artista organiza e apresenta visualmente os seus argumentos em suas obras.

Explorando os conceitos de Barthes sobre a retórica da imagem, constatamos que toda imagem é repleta de significados e que, ao se utilizarem mensagens linguísticas, seja pela ancoragem ou pelo revezamento, o orador freia essa polissemia e orienta seu auditório, direcionando-o àquilo que ele se propõe a demonstrar. Cildo escolhe quais as palavras e como colocá-las nas garrafas para que seus pensamentos ideológicos sobre a situação política brasileira sejam ao menos conhecidos pelo auditório que tem acesso às garrafas de Coca-Cola.

Metáfora, metonímia e ironia são figuras de retórica logo percebidas devido aos seus caracteres argumentativos reconhecidos na maneira como a obra de arte é conduzida. Referenciar-se à instituição econômica dominadora americana utilizando um de seus maiores símbolos de consumo, a Coca-Cola, e questionar o lugar e o fazer da arte tirando-a de seu espaço tradicional, desmitificando, inclusive, a figura do artista são questões levantadas por Meireles que, além dessas estratégias, faz alusão a importantes nomes e referências da própria história da arte. Questões essas que não podem ser afirmadas por nenhuma razão

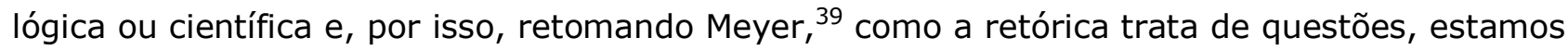
sempre nos pronunciando de alguma forma sobre ela.

Fernando Aparecido Ferreira: Doutor em Ciências da Comunicação pela ECA-USP (São Paulo), mestre em Comunicação Midiática pela UNESP (Bauru). É docente do Programa de PósGraduação em Linguística da Universidade de Franca (UNIFRAN). Vice-líder do grupo PARE Pesquisa em Argumentação e Retórica.

Fabíola Gonçalves Giraldi: Mestre em Linguística pela Universidade de Franca (UNIFRAN), especialista em Ensino e Pesquisa no Campo da Arte e da Cultura pela Universidade do Estado de Minas Gerais (UEMG), graduada em Artes Plásticas pela UEMG. É docente da Secretaria Municipal de Educação de Batatais (SP) e do curso de graduação em Artes Visuais da Universidade de Franca (UNIFRAN).

39 MEYER, Michel. Op. cit. 